\title{
Promoting solar thermal design: the Mechanical Engineering building at the University of New Mexico
}

\author{
A. A. Mammoli ${ }^{1}$, P. Vorobieff $^{1} \&$ D. Menicucci ${ }^{2}$ \\ ${ }^{1}$ Department of Mechanical Engineering, \\ The University of New Mexico, USA \\ ${ }^{2}$ Sandia National Laboratories, USA
}

\begin{abstract}
Thermal conditioning of buildings accounts for about half of the energy use in industrialized countries. Thus there is a considerable incentive to use renewable energy, especially solar, to heat and cool buildings. For small residential applications, 'passive' designs often suffice to cover most needs, however for larger, institutional buildings more technological 'active' measures are often required to provide thermal comfort. The Mechanical Engineering building at the University of New Mexico is an example of the latter class of building, in which a thermal solar panel array in combination with an absorption chiller and various energy saving measures results in a substantial reduction of energy requirements. At the same time, the building serves as an educational facility and a research laboratory for training future engineers in the field of renewables. The design of the building is presented, both in terms of its educational purpose and its energy saving measures. The performance of the building is also discussed.
\end{abstract}

\section{Introduction}

There is now widespread consensus in the scientific community that human activity (burning of fossil fuels) has already influenced Earth's climate [1], and that severe consequences are likely to result unless corrective action is taken [2]. At the same time, fossil fuel reserves are dwindling, with possibly disastrous effects, based on historical experience [3]. Despite this, political action to alleviate these 
problems is either non-existent (i.e. voluntary restrictions on greenhouse emissions) or largely ineffectual (Kyoto protocol). The reasons for this lack of action are complex and beyond the scope of the present work, however the best hope for a change is simple: education. There is an alarming amount of ignorance and misconception on the topic of energy in general, and renewable energy in particular. This ranges from total pessimism (hot showers will not be possible without burning fossil fuels) to overt optimism (solar powered cars). In reality, the switch from the fossil economy to a renewable (principally solar) economy will require major adjustment in both technology and economic infrastructure [4], and the time available to do this is limited [5]. Arguably, mechanical engineering students are the most effective target for an education in renewable energy, since it is they who will design energy systems of the future.

The transition to a renewables-based economy will necessitate serious changes in socio-economic systems: transportation, energy production and distribution, building design standards, and food production, to name a few. Some of these changes are difficult (e.g. transportation) while others, notably heating and cooling of buildings, are within easy reach of existing technology. In industrialized countries, a large fraction of the energy (approximately 50\%) is used in buildings. Of this fraction, a large proportion is consumed by heating, ventilation and air conditioning (HVAC) systems. A relatively small investment in proper design (architectural and mechanical) of buildings of all sizes will bring about massive returns. The design philosophy of the ME building at UNM is based on the principle that students who see that renewable energy is an effective substitute for fossil energy will contribute to the widespread use of renewables more than any energy policy debate.

\section{Historical background}

The University of New Mexico Mechanical Engineering building was designed and built towards the end of the energy crisis in the 1970s. The building envelope is highly insulated, with small windows (see Fig. 1), so that the load is internally dominated. In addition, massive internal concrete structures (stairwells, slabs) provide very high thermal inertia. A total of eight 50,000 liter water tanks serve as thermal storage, depending on seasonal requirements. In the warm months, the electric chillers 'charge' the tanks by cooling them to near freezing during the night. The cold water is circulated in the cooling coils during the following day, while the electric chiller is not operated. This procedure has a twofold advantage: the chiller COP is higher during the night due to the increased cooling tower performance, and electricity rates are lower, the latter reflecting the power utility company's base load requirements. A solar collector array of approximately $300 \mathrm{~m}^{2}$ (Energy Design Corporation XE-300 compound parabolic collector) was originally installed on the roof. The heat from the solar array was able to cover approximately $50 \%$ of the total building load in the coldest months. In the warm months, heat from the array was used to drive a Rankine cycle system (BarberNichols) which in turn drove a generator. 


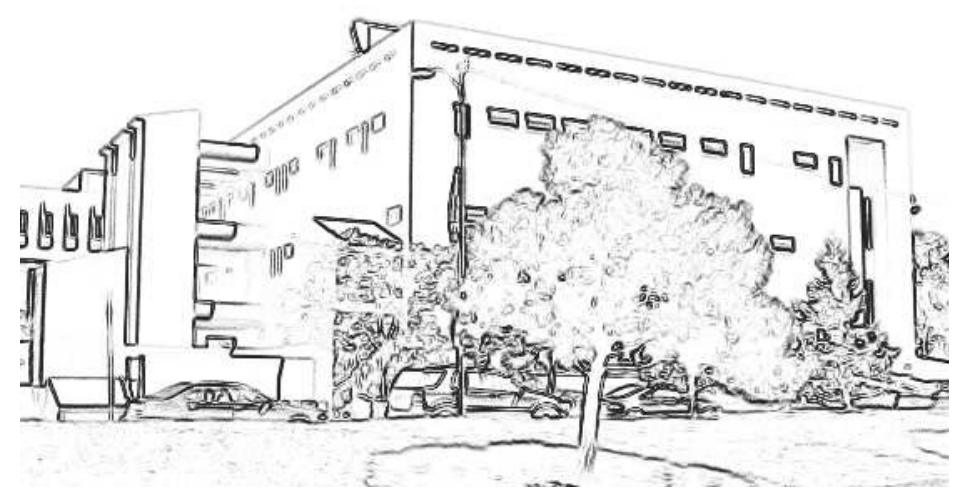

Figure 1: The Mechanical Engineering building at the University of New Mexico in Albuquerque.

As the Albuquerque Journal of October 12, 1980 put it, "The \$5.1M structure, UNM's first especially designed to conserve energy, is not only a teaching and office complex, but serves as a built-in laboratory used to educate students in techniques for analyzing energy use in buildings." At the inauguration ceremony in October 1980, Senator Pete Domenici (R-N.M.) said the University of New Mexico's new mechanical engineering building "represents a true step in the future of energy in our nation." Funding for monitoring and operation of the thermal system was provided by PNM (New Mexico's power utility company) and by Oak Ridge National Laboratory, for a period of two years.

Despite the promising building performance and the good intentions manifested in the building, the system was not maintained after the initial funding ended. It experienced a series of problems due to the lack of maintenance, and in combination with the waning interest in energy conservation and renewables beginning in the early 1980s, primarily as a consequence of the availability of extremely cheap fossil energy, it was progressively abandoned. Today, the Rankine engine has been salvaged, the solar collectors have deteriorated beyond repair and the electric chillers are used directly against the cooling load, bypassing the thermal storage.

Until recently, most ME students were completely unaware of the existence of energy conservation measures and solar energy collection which were an integral part of the building they inhabited. This ignorance can be considered as benign, as had the state of disrepair of the system been generally known, it might have contributed to the notion that renewable energy is impractical, expensive and unreliable. Sadly, this largely undeserved perception already extends to the wider community. 


\section{Modernization and refurbishment}

The first fossil energy crisis was largely a product of politics. The impendingcurrent one, on the other hand, is a result of resource depletion. Although there is still debate on the issue, there is mounting evidence that Hubbert's peak, where demand for oil overtakes supply, is either imminent or has already taken place [5]. As a consequence, energy conservation and renewable energy is again a topic of high interest. Funding from the Clean Energy Grants program, managed by the New Mexico Energy, Minerals and Natural Resources department, allowed the authors to begin a project to refurbish and modernize the solar-thermal system in the ME building. The decision to deviate from the original design was based on a combination of factors, first among which the requirement to avoid the equipment failures which were partly responsible for the demise of the original system. In addition, the system would be modernized to reflect of changes in technology that have taken place over the past 25 years. A simplified schematic of the thermal systems in the building is shown in Fig. 2.

One of the major problems with solar thermal installations is that they are generally used to provide a heat source for cold months, while they are unused in warmer months, making the economics less favorable. The original installation made use of the Rankine cycle unit to produce electricity, which could be used for a wide variety of applications including powering an electric chiller. However the Rankine engine has a number of disadvantages, principally complexity (leading to unreliability and vulnerability of the entire system), and low cycle efficiency (partially offset by the high COP of electric chillers). In the new design, in the summer the heat from the collectors is used to drive a single-stage absorption chiller (Yazaki), which will provide 20 tons of cooling capacity for approximately 6 hours / day.

The perception in the engineering community of absorption chillers merits a few remarks. Absorption chillers, single stage ones in particular, are often dismissed as low-efficiency machines, to be avoided if possible. When looked at in isolation, this is true: their typical COP of 0.7 is low compared to the typical COP of 4 for electric chillers. However, electric chillers use electricity, a high grade energy form which is produced predominantly by coal-fired power stations, which have an overall efficiency of $0.3-0.33$, not counting losses in the distribution grid. On the other hand, absorption chillers use low-grade heat (moderately hot water possibly by the sun or by waste heat). Viewed in combination with the source of power, the apparently huge thermodynamic efficiency advantage of the electric chiller is reduced considerably. If the impact of the energy source is accounted for, the absorption chiller becomes advantageous. It is hoped that the installation described here will serve to make students aware of the holistic nature of thermal system design.

\section{Building performance}

The thermal performance of the building was monitored immediately after the beginning of its occupancy, in 1981 and 1982, the effort being funded by a grant 


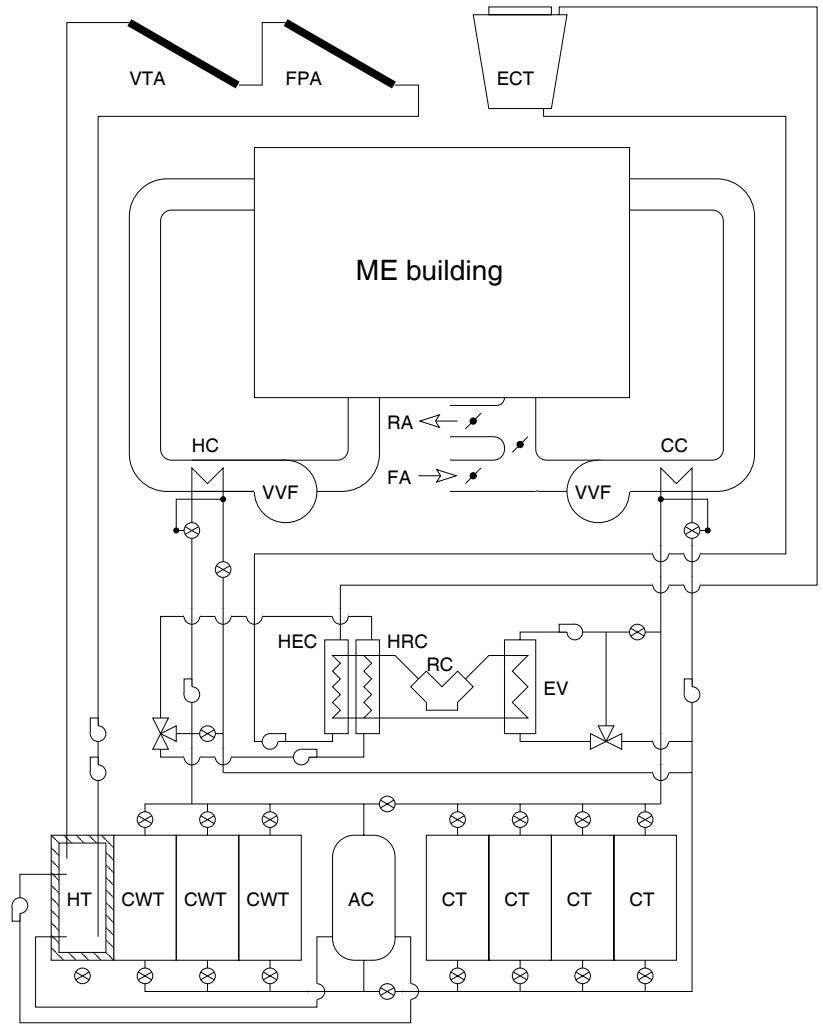

Figure 2: Schematic of the UNM-ME building thermal system. Key: VTA - vacuum tube array; FPA - flat plate array; ECT - evaporative cooling tower; HC - heating coil; CC - cooling coil; VVF - variable volume fan; RA relief air; FA - fresh air; HEC - heat extraction condenser; HRC - hear recovery condenser; $\mathrm{RC}$ - reciprocating compressor; EV - evaporator; HT - hot tank; CWT - cold / warm tank; CT - cold tank; AC - absorption chiller.

from Oak Ridge National Laboratory. Detailed results of the monitoring are available in the report by Wildin [6]. The principal results are briefly summarized here, focusing on the solar system performance and energy consumption of the building.

Data were recorded twice per minute, on a continuous basis, by a computerbased data acquisition system, for 20 months beginning in February 1981. Instrumentation included temperature sensors at the liquid inlets and outlets of most heat exchangers in the system, and a large number of temperature sensors in the stratified thermal storage tanks. Flow rates were also recorded for water, glycol and air in various parts of the system. Electrical energy use was monitored by watt-hour 
meters equipped with pulse generators. Finally, precision spectral pyranometers were used to monitor incident solar radiation.

A contractual requirement of the current refurbishment project is a minimum reduction of $20 \%$ in the heating and cooling costs for the ME building. Currently, many of the original energy conservation measures, such as the thermal storage tanks, are inactive. The heat pumps are used directly against the cooling and heating loads. The refurbishment will re-activate the original energy conservation systems. and the solar energy collected will be used directly to cool the building. Because the building characteristics have not changed substantially in the past 25 years, and because more recent data are not available, the 1981 data are assumed to be representative of the true building performance. Of particular interest are the heating and cooling loads for the building. These are shown in Fig. 3. The total cooling load is clearly much larger than the heating load. As a consequence, the decision to favor summer heat gain over winter heat gain in the refurbished system was made. The flat plate collectors (124 $\mathrm{m}^{2}$ absorber area, Lennox LSC18-1) will be mounted at an angle of $25^{\circ}$ to the horizontal, while the vacuum tube collectors (108 $\mathrm{m}^{2}$ absorber area, Sunda Seido 1-16) will be mounted at $35^{\circ}$ from the horizontal, equal to the latitude of Albuquerque, NM. This is in contrast to the previous arrangement, in which summer cooling was not implemented, and as a consequence the collectors were mounted at $45^{\circ}$, favoring heat collection in the winter.

Using a purpose-written computer code, the performance of the flat plate collectors and the vacuum tube collectors was estimated as a function of time of year, for both cooling conditions (average collector temperature of $95^{\circ} \mathrm{C}$ ) and for heating conditions (average collector temperature of $60^{\circ} \mathrm{C}$ ). The performance estimate takes into account the daily 30-year averaged temperatures for Albuquerque, as well as the position of the sun and the transverse and longitudinal incidence angle modifiers. In the cooling mode, a COP of 0.7 was assumed for the absorption chiller, while in the heating mode a heat loss of $10 \%$ was assumed in the heat storage system.

The predicted cooling and heating capacity of the solar system are plotted along with the measured heating and cooling loads in Fig. 3. From January to March, the solar collectors can provide most of the heat required by the building. In April and part of May, the solar-fired chiller can supply the required cooling to the building. In the hottest months, from mid-May to August, solar cooling accounts for approximately one third of the total cooling load. The fraction of cooling provided by solar energy increases starting in September, until in mid-October the system is switched to winter operating mode.

In 1981, the thermal performance of the building was quite exceptional: its annual purchased energy coefficient of $95.9 \mathrm{kWh} / \mathrm{m}^{2} \cdot \mathrm{yr}$ was approximately one third of the coefficient of the other buildings on campus, and approximately one half of the coefficient of an energy-conservative office building occupied at approximately the same time in Albuquerque. By today's standards, the building is still an excellent performer, using the same energy per unit area as the Adam Joseph Lewis Center for Environmental Studies in Oberlin, Ohio, occupied in 2000 [7]. 


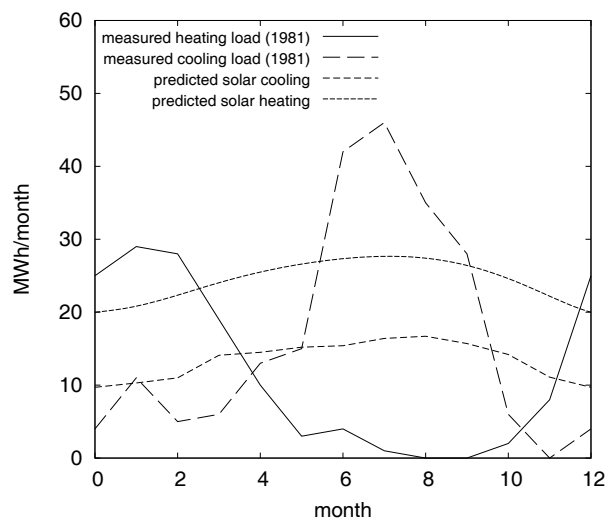

Figure 3: Heating and cooling load for the building measured in 1981, and estimated cooling and heating capacity of the solar thermal system.

The national average energy consumption for academic buildings is currently approximately three times that of the ME building.

The energy consumption of the electric chiller was metered for a period of 48 days beginning in late May 2006. The metered energy is approximately linear in time at about $43.86 \mathrm{kWh} / \mathrm{h}$. The chiller is rated at 110 tons cooling capacity. The COP was measured in the 1982 report by Wildin at 3.8, so that the monthly chilled water energy can be estimated at $124,000 \mathrm{kWh}$. This is far in excess of what was measured in 1981 for the same period, approximately $42,000 \mathrm{kWh} / \mathrm{month}$. The average energy consumption for 1981 is shown in Fig. 4 for comparison. The discrepancy could be caused by a variety of factors: the management of the HVAC system, in particular the fresh to recirculated air ratio; the increased cooling load of the building, due to the presence of many more personal computers; reduced efficiency of the chiller; meter calibration. The real cause is likely to be a combination of the above, and will be traced, and rectified, over the course of the system refurbishment.

\section{Curriculum development and graduate projects}

Undergraduate and graduate courses offer the best possibility of challenging conventional wisdom (or lack thereof), namely the mindless reliance on fossil energy. The audience is generally interested, and open to learning new concepts. Incorporating renewable energy concepts into 'core' courses such as Heat Transfer, Thermodynamics, and Heating, Ventilation and Air Conditioning Systems, serves the dual purpose of making the courses more interesting, and of introducing students to concepts to which usually they have only had peripheral exposure, perhaps through popular science broadcasting. For example, in the heat transfer course, the solar system, if properly instrumented, can be used as a laboratory to cover the standard 


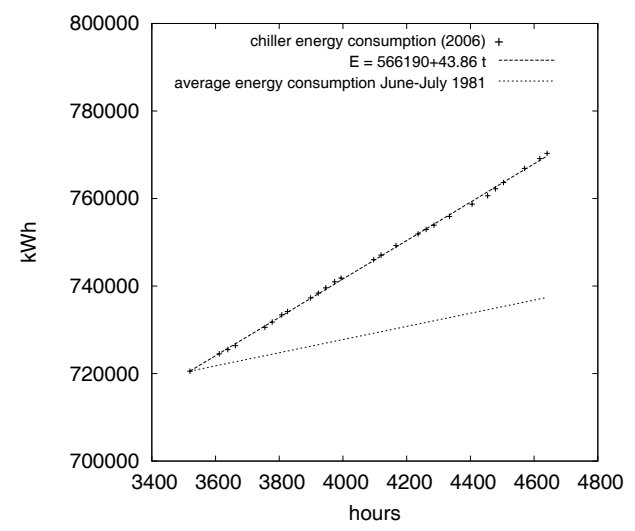

Figure 4: Current chiller energy consumption, compared to the energy consumption in 1981.

experimental program, including conduction, convection (internal and external) and thermal radiation. In each case, the 'real life' nature of the experiment is much more likely to stand out in the students' experience than the conventional 'canned' experiments. ME students are also required to attend a final year design course, where they must design and build a piece of equipment that performs a particular task. The solar system will provide an ideal workshop for this type of activity. Possible projects include night-time radiant coolers, combined PV-thermal panels, and various types of solar collector. A similar situation exists for the Thermal System Design \& Optimization course, and in fact the system has already served as the basis for one project in this course.

The ME department also offers three graduate-level courses directly related to the solar thermal system: Conduction, Convection, Radiation, and thermal Systems Design \& Optimization. Although these are theoretical in nature, the instrumentation of the solar system will make it possible to conduct experiments to compare theoretical predictions with measured data in great detail. Again, while this is standard practice, generally experiments are conducted on highly idealized laboratory apparatus, while it is not usual for the experiments to occur on a real working system of arguably great current interest, which would both give relevance to the theory associated to the experiment and expose students to the technical intricacies of thermal system design. Two new courses related to the system are planned: Sustainable Energy, and Solar System Design. By the time the curricula have been modified and new courses introduced, it will become possible to offer a certificate program in Solar Design.

Currently, three students are pursuing projects connected with the system: measurement and optimization of solar-assisted heating and cooling (MS), building performance simulation (MS), Holistic economics of solar thermal energy (PhD). The scope of the system is broad enough for several other graduate and under- 
graduate level projects, and an unusually high number of students have expressed interest in working on projects related to the system, demonstrating that the lack of research in the area of renewables in not due to lack of public interest, but to scarcity of resources.

\section{Perspectives}

The solar thermal system in the ME building is a stepping stone towards an engineering program in tune with the energy needs of the $21^{\text {st }}$ century The future of energy production and distribution will see a shift towards localized energy production and distribution (microgrids) as well as towards better load management for the current centralized grid. The U.S. Department of energy has provided funding to build a new control system for the ME building HVAC system, making it possible to respond to requests from the power generation utility to reduce demand in real time. The ME building will be the first of a series of buildings at UNM, and will demonstrate a web interface, automatic demand and response, use smart metering for load modeling and shifting. While load shaving is not entirely a new concept, the Gridwise concept introduces innovation in the sense that the load reduction will not necessarily result in deteriorating thermal conditions in the building, given the thermal storage ability and the solar assisted cooling, and improved forecasting abilities for weather conditions and electricity demand. In addition, real-time negotiation will take place, so that demand reduction in peak times can be offset with future rewards. When this strategy is applied to many building, it will become possible to offset the construction of new power stations intended to satisfy peak demand, and which remain idle for all but a small fraction of the year.

Another possibility is the installation of a photovoltaic (PV) array for the production of electricity to power the lighting, computers and experimental equipment. There are several parts of the building which could be used for such a purpose, including al large patio area, which could easily accommodate $400 \mathrm{~m}^{2}$ of cells, at the same providing a shaded area for students and faculty. In conjunction with energy-saving measures which will be installed during the course of regular maintenance, the PV-generated electricity could account for a good portion of the energy consumption for the building, it could become an active part of a microgrid, so that the building could become a net energy producer.

A third possibility for energy saving is to use night-time radiant cooling. This concept is gaining recognition in areas of the world where the majority of nights is clear and cool. Also because of the altitude (1618 m a.s.l) the night-time sky temperature is generally very low, and as a consequence it is possible to dissipate heat efficiently. In addition, the radiators can be located in places not suitable for either solar thermal or PV collectors.

Finally, research in the area of heat storage using phase change materials is made simple by the distribution of the thermal storage into several tanks. One of these could be isolated for research purposes without affecting the overall performance of the system. 


\section{References}

[1] Committee on Surface Temperature Reconstruction for the Last 2,000 years, (ed.) Surface Temperature Reconstruction for the Last 2,000 years. National Academies Press: Washington, DC, USA, 2006.

[2] Watson, R. \& the Core Writing Team, (eds.) IPCC, 2001: Climate Change 2001: Synthesis Report. A Contribution of Working Groups I, II, and III to the Third Assessment Report of the Intergovernmental Panel on Climate Change. Cambridge University Press: Cambridge, UK and New York, NY, USA, 2001.

[3] Diamond, J.M., Collapse: how societies choose to fail or succeed. Penguin Group: New York, NY, USA, 2005.

[4] Scheer, H., The solar economy: renewable energy for a sustainable global future. Earthscan: London, UK, 2002.

[5] Goodstein, D.L., Out of gas: the end of the age of oil. Norton and Co. Inc.: New York, NY, USA, 2004.

[6] Wildin, M.W., Results from use of thermally stratified water tanks to heat and cool the mechanical engineering building at the University of New Mexico. Technical Report ORNL/Sub/80-7967/1, Oak Ridge National Laboratory, 1982.

[7] Pless, S. \& Torcellini, P., Energy performance evaluation of a low-energy academic building. Technical Report NREL/CP-550-38962, National Renewable Energy Laboratory, 2005. 